\title{
Quantitative Determination of Antimony, Bismuth, and Tellurium in Geological Samples by Inductively Coupled Plasma Mass Spectrometry and Flow Injection Hydride Generation Atomic Absorption Technique
}

\author{
Manik C. Saha*, Rashmoni Baskey, Sudipta Lahiri, and Saikat Dutta \\ Geological Survey of India, Central Head Quarters, Chemical Division, \\ 15A \& B Kyd Street, Kolkata-700 016, India
}

\section{INTRODUCTION}

The determination of hydrideforming elements (As, $\mathrm{Sb}, \mathrm{Bi}$, Se, and Te) in geological materials is often required due to their industrial importance along with their toxic effects. They are used as a pathfinder for the exploration of ores (1-2). These elements tend to form dispersion halos around and above some less mobile ore-forming elements, and their presence in anomalies may indicate targets of mineral potential. Their use as a pathfinder or indicator of certain types of deposits containing Ag, Au, $\mathrm{Ni}, \mathrm{Co}, \mathrm{W}, \mathrm{Sn}, \mathrm{Mo}$, and $\mathrm{Cu}$ has been reported (3) and may also find "signature" elements for primary nonferrous metal smelting (4).

The determination of these elements in soil has been a great analytical challenge since geological samples are complex in nature and also due to the absence of sufficiently sensitive and robust analytical methods (5). Geological samples, e.g., soils, sediments, rocks, ores, minerals, etc., are normally brought into solution either by a fusion technique or using mixtures of mineral acids. Complete dissolution is recommended for geochemical exploration and geochemical mapping (6). Different dissolution techniques have been adopted to bring the geological samples in solution and measurement was carried out using several instrumental techniques. Halls et al. (5) studied the mutual interferences in the determination of these elements using hydride

\footnotetext{
*Corresponding author.
}

E-mail: mcs11gsi@gmail.com

\section{ABSTRACT}

An extensive study has been made for the accurate determination of antimony $(\mathrm{Sb})$, bismuth (Bi), and tellurium (Te) in soil and sediment samples at the $\mathrm{ng} / \mathrm{g}$ level by inductively coupled plasma mass spectrometry (ICP-MS). A comparison was made with the flow injection hydride generation accessory coupled with atomic absorption spectrometry (FI-HG-AAS). Samples of -200 mesh size were completely decomposed by a combination of hydrofluoric and perchloric acids, followed by extraction with $1: 1$ nitric acid for estimation of $\mathrm{Sb}, \mathrm{Bi}$, and $\mathrm{Te}$ by ICP-MS. The hydrochloric acid medium was maintained for estimation of the above elements by FI-HG-AAS

The accuracy of the proposed method was verified by analyzing 10 international soil and sediment reference samples. In addition, 20 soil and sediment samples, collected as per the guidelines of the National Geochemical Mapping Programme of the Geological Survey of India, were also analyzed. In order to investigate the precision of this method. Three sets of samples were digested separately and the mean of three replicates was considered for this study. A comparative study for the precision, accuracy, and quantification limits between the two techniques was also made. The limit of quantitation $(10 \sigma)$ achieved for $\mathrm{Sb}, \mathrm{Bi}$, and $\mathrm{Te}$ was in the $\mathrm{ng} / \mathrm{g}$ level for both techniques. generation inductively coupled mass spectrometry (HG-ICP-MS) by following two acid digestion procedures commonly used for geological materials and recommended the addition of $\mathrm{KI}$ and ascorbic acid for analysis, free from mutual interferences. Hydride-forming elements were estimated in geological samples with the help of flame atomic absorption spectrometry (FAAS) and flow injection hydride generation atomic absorption spectrometry (FI-HG-AAS) using a different combination of acids and fusion mixtures (7-8). Analytical techniques, such as instrumental neutron activation analysis (INAA), graphite furnace atomic absorption spectrometry (GFAAS), quartz tube atomic absorption spectrometry (QTAAS), inductively coupled plasma atomic emission spectrometry (ICP-AES), hydride generation atomic fluorescence spectrometry (HG-AFS), and the recently used sector field inductively coupled plasma mass spectrometry (SF-ICPMS), have been developed for the determination of these elements in environmental samples (9-14). To determine trace amounts of these elements in geological samples, the enrichment and separation of these elements from the matrix are often required, which is time-consuming and increases the risk of losses (1517). Although hydride generation improves the limits of detection, problems associated with the gen-

The abstract of this article was published in the 51st Chemist Convention conducted by the Indian Chemical Society and recognized by the Upadhyayula Annapurna and Satyanarayana memorial award. 
eration of the hydride species, plasma stability, and memory effect still exist and interferences from transition metals and hydride-forming elements have been reported (18). Methods for the determination of several of these elements in soil and sediment samples from a single sample are less well developed. Previous work on the analysis of geological materials includes the determination of various elemental groupings of As-Se, As-Sb, Se-Te, As-Sb-Te, As-Sb-Se, etc., using a combination of chemical procedures of separation and concentration which are time-consuming (19-22).

Several solvent extraction and precipitation methods have also been used for the pre-concentration and determination of these elements in geological samples at the nanogram level (23-26). The mutual interference warranting attention in the determination of Te by HG-ICPMS is that of As on Te, where an excess of As of 5000-fold can suppress the signal by 35\% (27). In case of HG-QTAAS, in the presence of As at 300-fold excess, only 50\% Te signal is reported (27). These drawbacks make them unsuitable for the routine analysis of trace amounts of $\mathrm{Sb}, \mathrm{Bi}$, and Te in geological samples. Hence, an accurate, precise, simple, and rapid method is required to fulfil these requirements.

In this work, it is proposed to establish a suitable, accurate, and precise methodology for the determination of these elements in geological samples and also to achieve detection limits at crustal abundance levels or below using the ICP-MS technique. It is a great challenge to achieve the detection limits at such a level for $\mathrm{Sb}, \mathrm{Bi}$, and Te without the use of pre-concentration. Interferences from high concentrations of other elements give erroneous results and the selection of isotopes may play a major role. ICP-MS, being a rapid multi-element detec- tion technique with very low detection limits, high sensitivity, small quantities, less interference, and a wide range of detection has been employed for this study. The presented dissolution and instrumentation technique overcomes almost all the possibilities of error. The limit of quantitation $(10 \sigma)$ achieved for the estimation of $\mathrm{Sb}, \mathrm{Bi}$, and $\mathrm{Te}$ is much less than the crustal abundance level and is also the required detection level for the Indian National Geochemical Mapping Programme. The validity of the method was checked for 10 standard reference materials (SRMs).

\section{EXPERIMENTAL}

\section{Instrumentation}

All analyses were performed using the PerkinElmer ${ }^{\circledR}$ ELAN $^{\circledR}$ DRC $^{\text {TM }}-\mathrm{e} \mathrm{ICP-MS}$ and the AAnalyst ${ }^{\mathrm{TM}}$ 700 FIAS instruments. The instrumental operating parameters for ICP-MS and FI-HG-AAS are listed in Tables I and II, respectively. The data acquisition parameters and isotopes used for ICP-MS measurement are listed in Tables III and IV, respectively.

TABLE I. Instrumental Parameters for ICP-MS

\begin{tabular}{llll}
\hline RF Power & $1150 \mathrm{~W}$ & Plasma Gas Flow & $17 \mathrm{~L} / \mathrm{min}$ \\
Nebulizer Gas Flow & $0.9 \mathrm{~L} / \mathrm{min}$ & Lens Voltage & Auto Lens \\
Auxiliary Gas Flow & $1.25 \mathrm{~L} / \mathrm{min}$ & Sample Uptake Rate & $1.0 \mathrm{~mL} / \mathrm{min}$ \\
\hline
\end{tabular}

TABLE II. Instrumental and Data Acquisition Parameters for HG-FI-AAS

\begin{tabular}{llll}
\hline Conditions & $\mathrm{Bi}$ & $\mathrm{Sb}$ & $\mathrm{Te}$ \\
\hline Light Sources & $\mathrm{EDL}$ & $\mathrm{EDL}$ & $\mathrm{EDL}$ \\
Lamp Current $(\mathrm{mA})$ & 360 & 380 & 380 \\
Wavelength $(\mathrm{nm})$ & 223.1 & 217.6 & 214.3 \\
Slit $(\mathrm{nm})$ & $0.7 \mathrm{~L}$ & $0.7 \mathrm{~L}$ & $0.7 \mathrm{~L}$ \\
Quartz Cell Temperature & $900^{\circ} \mathrm{C}$ & $900{ }^{\circ} \mathrm{C}$ & $900^{\circ} \mathrm{C}$ \\
Sample Volume $(\mu \mathrm{L})$ & 500 & 500 & 500 \\
Carrier & $10 \% \mathrm{HCl}$ & $10 \% \mathrm{HCl}$ & $10 \% \mathrm{HCl}$ \\
Pre-reductant & - & $10 \%(\mathrm{w} / \mathrm{v}) \mathrm{KI}$ & \\
& & and Ascorbic Acid & - \\
Reductant & $0.2 \% \mathrm{NaBH}$ & $0.2 \% \mathrm{NaBH}$ & $0.2 \% \mathrm{NaBH}$ \\
Measurement Mode & Peak Height & Peak Height & Peak Height \\
Solution Flow Rate & $2 \mathrm{~mL} / \mathrm{min}^{2}$ & $2 \mathrm{~mL} / \mathrm{min}$ & $2 \mathrm{~mL} / \mathrm{min}$ \\
\hline
\end{tabular}

TABLE III. Data Acquisition Parameters

\begin{tabular}{llll}
\hline Measuring Mode & Peak Hopping & Integration Time & $1000 \mathrm{~ms}$ \\
Point per Peak & 1 & Replicates & 3 \\
Number of Sweeps & 20 & Internal Standard & ${ }^{115} \mathrm{In}$ \\
Dwell Time & $50 \mathrm{~ms}$ & \\
\hline
\end{tabular}

TABLE IV. Isotopes for ICP-MS Analysis

\begin{tabular}{llll}
\hline Element & $\mathrm{Sb}$ & $\mathrm{Te}$ & $\mathrm{Bi}$ \\
Isotope & 121 & 128 & 209 \\
\hline
\end{tabular}




\section{Reagents}

All reagents used were of AnalR ${ }^{\circledR}$ grade. The $\mathrm{Sb}, \mathrm{Bi}$, and Te standards were prepared from $\mathrm{Sb}_{2} \mathrm{O}_{3}, \mathrm{Bi}_{2} \mathrm{O}_{3}$, and $\mathrm{TeO}_{2}$ which were obtained from Johnson and Matthey Chemical Ltd., Royston, U.K.

\section{Standard Solutions (100 ppm)}

The $\mathrm{Sb}, \mathrm{Bi}$, and Te standards (100 ppm) were prepared by dissolving $0.0599 \mathrm{~g}$ of $\mathrm{Sb}_{2} \mathrm{O}_{3}, 0.0557 \mathrm{~g}$ of $\mathrm{Bi}_{2} \mathrm{O}_{3}$, and $0.0625 \mathrm{~g}$ of $\mathrm{TeO}_{2}$ in (1:1) distilled $\mathrm{HNO}_{3}$. They were then made up to 500-mL volume with Milli-Q ${ }^{\circledR}$ water (Millipore Corporation, USA).

\section{Calibration Standards}

Amounts of $1 \mathrm{ppb}$ and $10 \mathrm{ppb}$ calibration standard solution of $\mathrm{Sb}$, $\mathrm{Bi}$, and Te were prepared by appropriate dilution of the $100-\mathrm{ppm}$ solution.

High purity Milli-Q ${ }^{\circledR}$ water (18 $\mathrm{m} \Omega-\mathrm{cm})$ and distilled nitric acid were used in all of the sample preparation procedures. All glassware and digestion vessels were acid-washed and rinsed with Milli-Q water.

\section{Certified Reference Materials (CRMs)}

The authors have chosen 10 CRMs obtained from the China National Analysis Centre for Iron and Steel, Beijing, P.R. China. The six certified sediment reference samples were GSD-3, GSD-4, GSD-5, GSD-6, GSD-11, and GSD-12, and the four certified soil reference samples were GSS-1, GSS-2, GSS-3, and GSS-7.

\section{Dissolution of Samples \\ ICP-MS}

A sample amount of $0.200 \mathrm{~g}$ was accurately weighed and transferred into a 30-mL Teflon ${ }^{\circledR}$ vessel, followed by addition of $8 \mathrm{~mL}$ of $\mathrm{HF}$ and $4 \mathrm{~mL}$ of $\mathrm{HClO}_{4}$. The beaker was covered and heated for about one hour and then the HF was evapo- rated slowly. The contents were heated at about $280{ }^{\circ} \mathrm{C}$ under covered conditions for two hours. The solution was then evaporated slowly to incipient dryness. The temperature was properly monitored at this stage in order to prevent loss of analyte. The contents were extracted with $25 \mathrm{~mL}$ of $8 \%$ $\mathrm{HNO}_{3}\left(8 \mathrm{~mL}\right.$ concentrated $\mathrm{HNO}_{3}$ diluted to $100 \mathrm{~mL}$ by Milli-Q ${ }^{\mathrm{TM}}$ water) and made up to $100-\mathrm{mL}$ volume with Milli-Q water. The solution was used for measurement of $\mathrm{Sb}, \mathrm{Bi}$, and Te by ICP-MS as per parameters shown in Table I, Table II, and Table III. A process blank was carried out following the same procedure as for the CRMs.

\section{FI-HG-AAS}

An accurate amount of $0.500 \mathrm{~g}$ sample was transferred into a Teflon ${ }^{\circledR}$ beaker and $4 \mathrm{~mL}$ nitric acid added, followed by addition of $4 \mathrm{~mL}$ perchloric and $8 \mathrm{~mL}$ hydrofluoric acid. The contents were kept standing overnight at ambient temperature. The next day, the sample was digested on a hot plate under covered conditions for one hour at a temperature of about $150^{\circ} \mathrm{C}$, and then at about $250^{\circ} \mathrm{C}$ until dissolution was completed. The solution was then evaporated to a pasty mass and extracted with $10 \mathrm{~mL}$ of 1:1 $\mathrm{HCl}$. The solution was made up to $50-\mathrm{mL}$ volume maintaining $10 \%$ $\mathrm{HCl}$. Measurement was made for $\mathrm{Bi}$ and Te using FI-HG-AAS as per parameters listed in Table II.

For the determination of $\mathrm{Sb}$, $2 \mathrm{~mL}$ of the above solution was separately reduced by adding $2 \mathrm{~mL}$ of KI-ascorbic acid, and measurement was made after appropriate dilution to a volume of $25 \mathrm{~mL}$.

\section{RESULTS AND DISCUSSION}

The present authors have chosen 10 soil and sediment reference materials for this study. Determination of $\mathrm{Sb}, \mathrm{Bi}$, and Te was made using ICP-MS together with FI-HGAAS. The isotopic masses of 121,
209, and 128 were selected for ICPMS measurement. The mass no. 128 has potential interferences from the inert gas element Xenon (Xe). A correction factor of $-0.072617^{*} \mathrm{Xe}$ 129 was used to minimize the interference. There is no interference on mass nos. 21 and 209 for $\mathrm{Sb}$ and $\mathrm{Bi}$, respectively. In case of FI-HGAAS, the hydrides of the elements are generated using $0.2 \% \mathrm{NaBH}_{4}$. A mixture of $10 \% \mathrm{KI}$ and ascorbic acid was used as the pre-reductant for the reduction of $\mathrm{Sb}-\mathrm{V}$ to $\mathrm{Sb}-\mathrm{III}$. The values observed by ICP-MS and HG-FI-AAS of the 10 CRMs are listed in the Table V. It can be seen that the analytical data obtained by ICPMS for all elements is very close to the certified values, thus confirming the accuracy of the methodology. The values observed by FI-HG-AAS are also close to the certified values, but the RSD (\%) is on the higher side due to interference of the sample matrix on the rate and quantity of the hydride formation.

The limit of quantitation (LOQ), defined as 10 times the standard deviation $(10 \sigma)$ of the process blank solution, was expressed as the concentration in the samples, thereby accounting for the dilution factor used, and was calculated as $20 \mathrm{ng} / \mathrm{g}$ for $\mathrm{Sb}, 20 \mathrm{ng} / \mathrm{g}$ for $\mathrm{Bi}$, and $5 \mathrm{ng} / \mathrm{g}$ for Te by ICP-MS measurement. The values of the LOQ, obtained without the need of any complicated separation and preconcentration steps, were comparable with or even better than the previously achieved detection limits using tedious separation and preconcentration steps (15-17). Quantification by FI-HG-AAS of Sb, $\mathrm{Bi}$, and Te could only be done above $100 \mathrm{ng} / \mathrm{g}, 100 \mathrm{ng} / \mathrm{g}$, and 50 $\mathrm{ng} / \mathrm{g}$, respectively. In order to investigate the precision of the methodologies, three separate sets of solutions were prepared for instrumental measurement and the mean of three replicate measurements was taken. The relative stan- 
dard deviation (RSD), was calculated as $<5 \%$ for the ICP-MS measurements, whereas for FI-HGAAS it was found to be about $10 \%$. The results in Table $\mathrm{V}$ show that the detection limits, precision, and accuracy for ICP-MS are better than of the FI-HG-AAS technique using a very simple and rapid method. Hence, the ICP-MS measurement is preferred over FI-HG-AAS.

In addition, 20 soil and stream sediment samples collected from the Phek district, Nagaland, India (Toposheet No. 83K/10) under the NGCM program were also studied. These samples were analyzed by the proposed methodology and uniform recovery of $\mathrm{Sb}, \mathrm{Bi}$, and Te was observed and the results are listed in Table VI. The precision of the proposed method was also checked by analysis of these samples following the same procedure as for the CRMs. The estimated RSD value was found to be $<5 \%$ for $\mathrm{Sb}$ and $\mathrm{Bi}$, whereas for Te, it was $<10 \%$ confirming good precision of the proposed methodology.

\section{CONCLUSION}

The developed method using ICP-MS is simple, fast, sensitive, and promising for routine ICP-MS analysis of trace amounts of $\mathrm{Sb}, \mathrm{Bi}$, and Te in geological samples. A comparative study of precision, accuracy, and the limit of quantitation $(10 \sigma)$ between two techniques has also been made. It was observed that the ICP-MS technique is superior to FI-HG-AAS. This method is adopted by the Geological Survey of India for routine analysis of $\mathrm{Sb}, \mathrm{Bi}$, and $\mathrm{Te}$ in geological samples at crustal abundance levels collected under the National Geochemical Mapping Programme. The LOQ for $\mathrm{Sb}, \mathrm{Bi}$, and Te was found to be $20 \mathrm{ng} / \mathrm{g}$, $20 \mathrm{ng} / \mathrm{g}$, and $5 \mathrm{ng} / \mathrm{g}$, respectively.

\section{ACKNOWLEDGMENT}

The authors are grateful to the Director General, Geological Survey of India, for giving permission to publish this work. Thanks are also due to Shri C. Shijoh, Geologist, for collection of the geological samples.

Received April 8, 2016.

\section{REFERENCES}

1. C.B. Moore and J.A. Canepa, Anal. Chem. 57, 88 (1985).

2. R. Ellsmore, S. Buckman and C. Simpson, NEO 143 (2010).

3. R.W.Boyle, Geol. Surv. Can. Pap. 74, 75 (1974).

4. M.E. Ketterer, J.H. Lowry, J. Simon, Jr., K. Humphries, and M.P. Novatnak, Appl. Geochem. 16, 207 (2001).

5. G.E.M. Hall, J.C. Pelchat, J. Anal. At. Spectrom. 12, 97 (1997).

6. T. T. Chao and R. F. Sanzolone, J. Geochem. Expl. 44, 65 (1992).

7. H. Matusiewiez and M. Krawezyk, Spectrochim. Acta B 62, 309 (2007).

8. P. Chattopadhyay and S.S Nathan, Analyst 116, 1145 (1991).

9. S. Terashima, Geostand. Newsl. 25, 127 (2001)

10. A. Forrest, R. Kingsley, J.G. Schilling, Geostand. Geoanal. Res. 33, 261 (2009).

11. Z.C. Hu, S. Gao, D. Gunther, S.G. Hu, X.M Liu, and H.L Yuan, Appliied Spectrosc. 60, 781 (2006).

12. E.P. Mignonsin and I. Roelandts, Chem. Geol. 16, 137 (1975).

TABLE V

Results of Sb, Te, and Bi in SRMs by FI-HG-AAS and ICP-MS

\begin{tabular}{lccccccccc}
\hline Sample ID & \multicolumn{3}{c}{$\begin{array}{c}\text { Sb (ppm) } \\
\end{array}$} & $\begin{array}{c}\text { Observed } \\
\text { FI-HG-AAS ICP-MS }\end{array}$ & Certified & \multicolumn{3}{c}{$\begin{array}{c}\text { Te }(\mathrm{ppm}) \\
\text { Observed }\end{array}$} & \multicolumn{3}{c}{ Certified } & \multicolumn{3}{c}{ Bi (ppm) } \\
Observed & Certified \\
\hline GSD-12 & 26.83 & 22.77 & $24 \pm 4$ & 0.25 & 0.27 & $0.29 \pm 0.07$ & 12.25 & 10.4 & $10.9 \pm 1.3$ \\
GSD-11 & 13.16 & 14.23 & $14.9 \pm 1.8$ & 0.32 & 0.34 & $(0.36)$ & 44.68 & 51.4 & $50 \pm 5$ \\
GSD-6 & 1.96 & 1.35 & $1.25 \pm 0.33$ & 0.17 & 0.12 & $(0.13)$ & 7.3 & 5.16 & $5.0 \pm 0.6$ \\
GSD-5 & 3.35 & 3.73 & $3.9 \pm 0.7$ & 0.10 & 0.12 & $0.12 \pm 0.03$ & 1.98 & 2.30 & $2.4 \pm 0$. \\
GSD-4 & 2.42 & 1.85 & $1.84 \pm 0.27$ & 0.05 & 0.067 & $(0.07)$ & 0.72 & 0.69 & $0.64 \pm 0.15$ \\
GSD-3 & 6.7 & 5.15 & $5.4 \pm 0.8$ & 0.17 & 0.15 & $0.14 \pm 0.03$ & 0.98 & 0.79 & $0.79 \pm 0.14$ \\
GSS-7 & 0.39 & 0.47 & $0.42 \pm 0.13$ & 0.052 & 0.046 & $(0.047)$ & 0.16 & 0.19 & $0.20 \pm 0.07$ \\
GSS-3 & 0.64 & 0.46 & $0.45 \pm 0.15$ & 0.051 & 0.041 & $0.040 \pm 0.015$ & 0.15 & 0.16 & $0.17 \pm 0.06$ \\
GSS-2 & 1.58 & 1.25 & $1.3 \pm 0.3$ & n.d. & 0.031 & $(0.035)$ & 0.38 & 0.37 & $0.38 \pm 0.06$ \\
GSS-1 & 1.62 & 0.88 & $0.87 \pm 0.32$ & 0.055 & 0.047 & $(0.047)$ & 1.4 & 1.26 & $1.2 \pm 0.2$ \\
\hline
\end{tabular}

n.d. = not detected. 


\section{Atomic

TABLE VI

Results of Sb, Bi, and Te by ICP-MS

\begin{tabular}{cccccc}
\hline Sample No. & Sample I.D. & Sample Nature & \multicolumn{3}{c}{ Observed Values $(\mu \mathrm{g} / \mathrm{g})$} \\
& & & $\mathrm{Sb}$ & $\mathrm{Bi}$ & $\mathrm{Te}$ \\
\hline $15564-7$ & $83 \mathrm{~K} 10 / 019 / \mathrm{S} / 14$ & Stream Sediment & 0.53 & 0.37 & 0.03 \\
$15564-8$ & $83 \mathrm{~K} 10 / 020 / \mathrm{S} / 14$ & Stream Sediment & 0.57 & 0.46 & 0.02 \\
$15564-9$ & $83 \mathrm{~K} 10 / 030 / \mathrm{S} / 14$ & Stream Sediment & 0.72 & 0.97 & 0.03 \\
$15564-13$ & $83 \mathrm{~K} 10 / 043 / \mathrm{S} / 14$ & Stream Sediment & 0.77 & 0.52 & 0.02 \\
$15564-14$ & $83 \mathrm{~K} 10 / 044 / \mathrm{S} / 14$ & Stream Sediment & 0.51 & 0.40 & 0.03 \\
$15564-15$ & $83 \mathrm{~K} 10 / 045 / \mathrm{S} / 14$ & Stream Sediment & 1.42 & 0.42 & 0.02 \\
$15564-20$ & $83 \mathrm{~K} 10 / 069 / \mathrm{S} / 14$ & Stream Sediment & 0.49 & 0.57 & 0.03 \\
$15564-25$ & $83 \mathrm{~K} 10 / 085 / \mathrm{S} / 14$ & Stream Sediment & 0.63 & 0.53 & 0.03 \\
$15564-26$ & $83 \mathrm{~K} 10 / 096 / \mathrm{S} / 14$ & Stream Sediment & 0.75 & 0.59 & 0.04 \\
$15564-27$ & $83 \mathrm{~K} 10 / 097 / \mathrm{S} / 14$ & Stream Sediment & 0.81 & 0.54 & 0.04 \\
$15564-28$ & $83 \mathrm{~K} 10 / 098 / \mathrm{S} / 14$ & Stream Sediment & 0.66 & 0.52 & 0.05 \\
$15564-29$ & $83 \mathrm{~K} 10 / 099 / \mathrm{S} / 14$ & Stream Sediment & 0.73 & 0.60 & 0.03 \\
$15564-30$ & $83 \mathrm{~K} 10 / 111 / \mathrm{S} / 14$ & Stream Sediment & 0.62 & 0.55 & 0.02 \\
$15564-31$ & $83 \mathrm{~K} 10 / 112 / \mathrm{S} / 14$ & Stream Sediment & 0.53 & 0.46 & 0.02 \\
$15564-33$ & $83 \mathrm{~K} 10 / 144 / \mathrm{S} / 14$ & Stream Sediment & 0.80 & 0.53 & 0.02 \\
$15564-34$ & $83 \mathrm{~K} 10 / 087 / \mathrm{S} / 14$ & Stream Sediment & 0.15 & 0.05 & 0.03 \\
$15564-35$ & $83 \mathrm{~K} 10 / 088 / \mathrm{S} / 14$ & Stream Sediment & 0.79 & 0.53 & 0.05 \\
$15564-36$ & $83 \mathrm{~K} 10 / 101 / \mathrm{S} / 14$ & Stream Sediment & 0.19 & 0.10 & 0.04 \\
$15564-38$ & $83 \mathrm{~K} 10 / 114 / \mathrm{S} / 14$ & Stream Sediment & 0.49 & 0.37 & 0.05 \\
$15564-39$ & $83 \mathrm{~K} 10 / 117 / \mathrm{S} / 14$ & Stream Sediment & 0.81 & 0.56 & 0.04 \\
\hline
\end{tabular}

13. J. Zheng, M. Yamada, and S. Yoshida, J. Anal. At. Spectrom. 26, 1790 (2011)

14. G. Yang, J. Zheng, K. Tagami, and S. Uchida, Talanta 116, 181 (2013).

15. E. Kontas, H. Niskavaara, and J. Virtasalo, Geostand. Newsl. 14, 477 (1990).

16. S. Terashima, Geostand. Newsl. 25, 127 (2001).

17. G.E.M. Hall and J.C. Pelchat, Geostand. Newsl. 21, 85 (1997).

18. L.S. Zhang and S.M. Combs, J. Anal. At. Spectrom. 11, 1043 (1996).

19. Branch and Hutchinson, Analyst 110, 163 (1985).

20. L. Ebdon and Wilkinson, Anal. Chim. Acta 194, 177 (1987).

21. H. Niskavaara and E. Kontas, Anal. Chim. Acta 231, 273 (1990).

22. B.C Severne and R.R. Brooks, Talanta 19, 1467 (1972).
23. I.H. Woo, K.Watanabe, Y. Hashimoto and Y.K. Lee, Anal. Sci. 3, 49 (1987).

24. B. Ebarvia, E. Macalalad, N. Rogue and I. Rubeska, J. Anal. At. Spectrom. 3, 199 (1988).

25.A.B. Volynsckii, N.N. Baranova and T.G. Darina, Zh. Anal. Khim. 45, 378 (1990).

26. P. Auscavage, J. Res. U.S. Geol. Surv. 5, 405 (1977)

27. G.E.M. Hall, A.I. Maclaurin, J.C. Pelchat, and G. Gauthier, Chem. Geol. 137, 79 (1997). 